Published in final edited form as:

Am J Med Genet A. 2016 February ; 170A(2): 386-391. doi:10.1002/ajmg.a.37461.

\title{
Novel FANCI mutations in Fanconi anemia with VACTERL association.
}

\section{SA Savage ${ }^{1}$, BJ Ballew ${ }^{1}$, N Giri $^{1}$, NCI DCEG Cancer Genomics Research Laboratory ${ }^{2}$, SC Chandrasekharappa ${ }^{3}$, N Ameziane ${ }^{4}$, J de Winter ${ }^{4}$, BP Alter ${ }^{1}$, NCI DCEG Cancer Sequencing Working Group ${ }^{1}$}

1Division of Cancer Epidemiology and Genetics, National Cancer Institute, Rockville, Maryland. ${ }^{2}$ Cancer Genomics Research Laboratory, Leidos Biomedical Research, NCl-Frederick, Rockville, Maryland. ${ }^{3}$ Cancer Genetics and Comparative Genomics Branch, National Human Genome Research Institute, Bethesda, Maryland. ${ }^{4}$ Department of Clinical Genetics, Vrije Universiteit Medical Center, Amsterdam, The Netherlands.

\begin{abstract}
Fanconi anemia (FA) is an inherited bone marrow failure syndrome caused by mutations in DNA repair genes; some of these patients may have features of the VACTERL association. Autosomal recessive mutations in FANCI are a rare cause of FA. We identified FANCI mutations by next generation sequencing in three patients in our FA cohort among several whose mutated gene was unknown. Four of the six mutations are novel and all mutations are likely deleterious to protein function. There are now 16 reported cases of FA due to FANCI of whom 7 have at least 3 features of the VACTERL association (44\%). This suggests that the VACTERL association in patients with FA may be seen in patients with FANCI mutations more often than previously recognized.
\end{abstract}

\section{Keywords}

FANCI; Fanconi anemia; VACTERL association

\section{INTRODUCTION}

Fanconi anemia (FA) is a cancer-prone inherited bone marrow failure syndrome (IBMFS) caused by germline mutations in key components of the DNA damage response. Eighteen known FA subtypes account for about $95 \%$ of cases. Subtypes A, C, D1 (BRCA2), D2, E, F, G, I, J (BRIPI), L, M, N (PALB2), O (RAD51C), P (SLX4), Q (ERCC4), S (BRCA1), and $\mathrm{T}(U B E 2 T)$ are inherited in an autosomal recessive pattern [Kitao and Takata, 2011; Bogliolo et al., 2013; Hira et al., 2015; Sawyer et al., 2015]. FANCB is X-linked recessive. FANCA, FANCB, FANCC, FANCE, FANCF, FANCG, FANCL, and FANCM comprise the FA core complex and interact with FANCD2 and FANCI, which then interact with FANCD1/BRCA2, FANCN/PALB2, FANCJ/BRIP1/BACH1, FANCP/SLX4, and FANCO/ RAD51C, as well as NBS1, BRCA1, and FAN1 to preserve genome integrity [Kitao and Takata, 2011]. Germline mutations in the genes encoding these proteins result in deficient DNA repair [Kitao and Takata, 2011]. The diagnostic test for FA is the detection of 
increased chromosomal breakage in cells cultured with a clastogen, such as diepoxybutane (DEB) or mitomycin C (MMC) [Fargo et al., 2014].

In addition to progressive bone marrow failure (BMF) in childhood and an elevated risk of cancer, many patients with FA also have congenital malformations such as radial bone and thumb abnormalities, short stature, skin hyperpigmentation, and/or café au lait macules [Shimamura and Alter, 2010]. A subset of patients with FA has a constellation of features consistent with the VACTERL-H (vertebral anomalies, anal atresia, cardiac anomalies, tracheal-esophageal fistula, esophageal atresia, renal structural abnormalities, limb anomalies, and hydrocephalus) association [Solomon et al., 2010]. To date, the VACTERL association in FA has been reported in patients with mutations in FANCA, FANCB, FANCC, FANCD1/BRCA2, FANCD2, FANCE, FANCF, and FANCG [Alter and Rosenberg, 2013]; it appears to be present in other genotypes as recently reported in FANCL and described in this report [Vetro et al., 2015].

We report three unrelated patients with FA and the VACTERL phenotype due to previously unreported autosomal recessive FANCImutations, and review the literature on the clinical features and mutations of 13 previously reported cases with FANCI mutations [Levitus et al., 2004; Dorsman et al., 2007; Sims et al., 2007; Scheckenbach et al., 2012].

\section{METHODS}

\section{Patients}

Families with FA and their relatives are participants in an IRB-approved longitudinal cohort study at the National Cancer Institute (NCI) entitled "Etiologic Investigation of Cancer Susceptibility in Inherited Bone Marrow Failure Syndromes" (www.marrowfailure.cancer.gov, NCI 02-C-0052, ClinicalTrials.gov Identifier: NCT00027274). Patients and their family members complete detailed family history and medical history questionnaires. All participants or their guardians provided written informed consent in accordance with Health and Human Services regulation 45 CFR 46. We conduct detailed medical record review, collect biospecimens, and perform thorough clinical evaluations of affected individuals and their relatives at the NIH Clinical Center [Alter et al., 2010]. All cases were confirmed by chromosomal breakage analysis using DEB and MMC [Fargo et al., 2014]. The three cases reported here are the only three with FANCI in our cohort of 141 patients with FA, of which 18 have the VACTERL association.

\section{Sequence Analyses}

We performed whole exome sequencing (WES) on two probands with FA (NCI-82-1 and NCI-309-1) and their healthy relatives at the NCI's Cancer Genomics Research Laboratory as previously described ([Ballew et al., 2013; Kocak et al., 2014], respectively). Sequencing on the third proband (NCI-253-1) was performed with a custom Haploplex kit (Agilent Technologics, Inc., Santa Clara, CA), which was enriched for the coding regions of all known FA genes as described [Naipal et al., 2014]. Barcoded sequence libraries were sequenced on the Miseq using 150 bp paired-end protocol and Surecall version 2.0 software was used for the data analysis. All variants were filtered based on autosomal recessive 
inheritance that included both homozygous and compound heterozygous states as well as rarity in publicaly available databases. We also specifically evaluated known FA-associated genes for variants in our patients. In silico evaluation of variants was performed with multiple algorithms and compared with known variants in the FA database (http:// www.rockefeller.edu/fanconi/), Supplementary Table SI. Mutations in FANCI were validated using the SMRTbell Template Prep Kit and sequenced on a Pacific Biosciences RS according to the manufacturer's instructions, or through whole-gene sequencing as described [Chandrasekharappa et al., 2013]. The FANCI reference sequences used were NM_001113378.1 and NP_001106849.1.

\section{RESULTS \\ Case $\mathrm{NCl}-82-1$}

Patient NCI-82-1 was noted to have multiple congenital anomalies at her birth at 38 weeks gestation to non-consanguineous parents of Northern European and American Indian ancestry (Table I). FA was suspected at birth and the diagnosis confirmed at 3 months of age due to elevated chromosomal breakage in the presence of clastogens.

NCI-82-1 was evaluated at NIH at age 5 9/12 years. At that time, she had marked short stature with height and weight below the 1st centile for age (height Z-score -5.24 and weight Z-score -4.9), microcephaly (head circumference $44 \mathrm{~cm}$; 50th centile for an 8 months old), and a small triangular face ("Fanconi facies"). Her constellation of congenital anomalies was consistent with the VACTERL association (fused cervical vertebrae, atrial septal defect [ASD], ventricular septal defect [VSD], duodenal atresia, small kidneys, and absent thumbs). She also had many features seen in FA (Table I). At that time, she had mild thrombocytopenia with a platelet count of $120^{9} / \mathrm{L}$. Her bone marrow was hypocellular (30\%) with a 47,XX,+i(1)(q10)[2]/46,XX[48] clonal abnormality.

Her cytopenias progressed over time and she was treated with etanercept for 6 months at 8.5 years of age without a response. She underwent HLA-matched sibling donor hematopoietic stem cell transplantation (HSCT) at age 10.5 years with successful engraftment. Unfortunately, she developed acute and chronic graft versus host disease (GvHD) and died from multi-organ failure 11 months after HSCT.

Analysis of WES data for NCI-82-1 was performed under an autosomal recessive inheritance model that included homozygous or compound heterozygous variants. The proband NCI-82-1 had two mutations present in FANCI, one deletion (chr15:89857921_89857924delCTTT, c.3799_3802delCTTT [NM_001113378.1], p.Ser1268Argfs*5 [NP_001106849.1]) and one insertion (chr15:89858595_89858596insG, c.3899_3900insG, p.Asp1301Glyfs*3) (Fig. 1). The deletion and insertion both cause alterations in the reading frame that result in premature stop codons and the loss of 61 or 28 amino acids from the $\mathrm{C}$-terminus, respectively. The unaffected sibling and one parent were both carriers of only the insertion. The other parent's DNA was not available but long range sequencing analysis confirmed that the two mutations affected separate alleles. 


\section{Case $\mathrm{NCl}-253-1$}

NCI-253-1 was a female with the VACTERL association and FA anomalies (Table I). She was born via $\mathrm{C}$-section at 34 weeks gestation due to fetal distress to non-consanguineous parents of European and Hispanic ancestry. NCI-253-1 was diagnosed with FA at age 5 months based on elevated chromosome breakage. She was diagnosed with hypothyroidism at 2 years, 9 months of age.

She was evaluated at NIH at age 3 years. She had marked short stature (height Z-score -3.7 and weight Z-score $-2.85 \mathrm{SD}$ ), microcephaly (head circumference $45 \mathrm{~cm}$; 50th centile for 1 year old), and a small triangular face ("Fanconi facies"). Her congenital anomalies were also consistent with the VACTERL association (cervical vertebral anomaly, VSD, patent foramen ovale, horseshoe kidney, and absent thumb). Her blood counts were normal but her bone marrow was hypocellular (40\%) with normal cytogenetics (46,XX[20]).

WES of NCI-253-1 identified compound heterozygous mutations in FANCI. There was one novel mutation p.Cys1014Tyr (c.3041G >A, chr15:89847129G $>$ A) and one previously reported mutation (c.1461T>A, p.Tyr487X, chr15:89824480T>A) (Fig. 1). Targeted sequencing revealed that one parent carried the Cys1014Tyr mutation and the other carried the Tyr487X mutation.

\section{Case NCl-309-1}

Case NCI-309-1 was born to non-consanguineous parents of Asian, Hispanic, European, and Native American ancestry. She is one of fraternal twins conceived by in vitro fertilization. NCI-309-1 and her healthy brother were delivered by C-section at 32 weeks for fetal distress. At birth, she was noted to have bilateral hypoplastic thumbs, microcephaly, and congenital heart disease (ASD, VSD, and PDA, all of which closed spontaneously) (Table I). A chromosome breakage test performed soon after birth was consistent with FA. Evaluation of NCI-301-1 at 8 years of age revealed microcephaly, a small, triangular face ("Fanconi facies"), small eyes, small neck, narrow C5 vertebra, bilaterally hypoplastic thumbs, absent radial pulses, Chiari malformation, and a small pituitary gland with poorly visualized pituitary stalk. She had previously undergone a bilateral ureteric reimplantation for grade three vesicoureteral reflux. Several of these birth defects were consistent with VACTERL. She also had normal stature and normal hormone function. Mild neutropenia was present with an ANC $0.92 \times 10^{9} / \mathrm{L}$. Her hemoglobin was $12.8 \mathrm{gm} / \mathrm{dL}$, MCV $88.2 \mathrm{fL}$, platelets $257 \times$ $109 / \mathrm{L}$, and $\mathrm{HbF} 2.6 \%$. A bone marrow biopsy revealed $20-50 \%$ cellularity with trilineage hematopoiesis and normal cytogenetics $(46, \mathrm{XX}[20])$.

Analysis of WES data for the NCI-309 family was performed under an autosomal recessive inheritance model that included homozygous or compound heterozygous variants. The proband NCI-309-1 had two mutations present in FANCI, p.Ser347Pro (c.1039T >C, chr15: 89817462T>C) and p.Gly401Glufs*3 (c.1201_1201delG, chr15:89820030_89820030delG) (Fig. 1). One parent carried the p.Ser347Pro mutation whereas the other parent carried the p.Gly401Glufs*3 mutation. 


\section{DISCUSSION}

Autosomal recessive mutations in $F A N C I$ were first reported in 2007 and are a relatively rare subgroup of FA [Levitus et al., 2004; Dorsman et al., 2007; Sims et al., 2007;

Shimamura and Alter, 2010; Scheckenbach et al., 2012; Chandrasekharappa et al., 2013]. Our identification of three previously uncharacterized individuals with FA caused by compound heterozygous mutations in FANCI brings the total of reported cases of FA due to FANCI mutations to 16.

We identified six FANCI mutations in three probands, two of which have been previously reported in FA (p.Tyr487X and p.Gly401Glufs*3). All six mutations are predicted to have deleterious effects on protein function. Four of the mutations result in premature termination codons (p.Tyr487X in NCI-253, p.Ser1268Argfs*5, and p.Asp1301Glyfs*3 in NCI-82, and Gly401Glufs*3 in NCI-309) (Fig. 1). While the transcripts encoding p.Tyr487X and p.Gly401Glufs*3 most likely undergo nonsense mediated decay, p.Ser1268Argfs*5 and p.Asp1301Glyfs*3 may result in a translated protein lacking an EDGE motif and a Cterminal arginine/lysine rich nuclear localization sequence. A previously described FANCI mutation (p.Arg1299X) that results in a similar truncation to p.Ser1268Argfs*3 and p.Asp1301Glyfs*5 exhibits reduced nuclear localization [Colnaghi et al., 2011]. The same report demonstrated that the EDGE motif contributes to resistance to DNA crosslinking [Colnaghi et al., 2011]. The two missense mutations, p.Ser347Pro and p.Cys1014Tyr, affect highly conserved positions and are located in the first helical domain and third solenoid domain, respectively (Fig. 1). They are quite distant from the FANCI-FANCD2 interface, but are near amino acids important for DNA binding [Joo et al., 2011]. Cys1014 is in the armadillo repeat region [Smogorzewska et al., 2007], a structural domain that has been implicated in mediating protein-protein interactions (Fig. 1).

Notably, the three FA cases due to FANCI mutations reported here all had features consistent with the VACTERL association. Four of the 13 previously published cases of FA due to FANCI mutations reported enough clinical information to conclude that they, too, had the VACTERL association [Levitus et al., 2004; Dorsman et al., 2007; Sims et al., 2007; Scheckenbach et al., 2012]. Thus, 7 of the 16 cases of FA due to FANCI mutations (44\%) have FA in the setting of the VACTERL association. This is significantly higher than the value of 5\% for all FA complementation groups among 245 patients with FA ( $P=0.00008$, binomial probability test) [Faivre et al., 2005]. In that report, which was prior to the discovery of FANCI, the VACTERL association appeared to occur primarily in individuals with the D1, E, and F complementation groups, and less commonly in those in A, C, and G. A subsequent systematic review of 2,245 cases of FA reported in the literature identified 108 cases with three or more features of the VACTERL association [Alter and Rosenberg, 2013]. Three of the 42 FA VACTERL cases with genetic data (7\%) had FANCI mutations. Additionally, VACTERL features were more frequent than predicted in individuals with $F A N C B, D 1, D 2, J, N$, and $O$ in our previous report [Alter and Rosenberg, 2013].

The VACTERL association is identified by the finding of any three features among the seven or eight heterogeneous findings, and may be sporadic, or due to underlying genetic disorders such as FA. Those with FA usually have FA-specific anomalies that are not part of 
VACTERL, such as microcephaly, microophthalmia, hearing loss, café au lait macules, and others [Shimamura and Alter, 2010]. We recently identified an FA-specific subset of VACTERL due to the combined presence of radial ray and renal structural anomalies which was present in all of the FANCI patients who met VACTERL criteria (Table I) [Alter and Rosenberg, 2013]. This is quite different from the usual cluster of vertebral defects, cardiac malformations, and renal anomalies, although those were found in our patients as well [Solomon et al., 2010]. The identification of patients with FA among those with VACTERL association has important prognostic, therapeutic, and reproductive implications, and warrants referral to hematologists and genetic counselors.

In summary, we have characterized three patients with FA and the VACTERL association caused by autosomal recessive mutations in FANCI. Data from these patients and limited data from cases reported by others suggest that mutations in FANCI may be added to the FA genotypes in which the VACTERL association is unusually frequent.

\section{Supplementary Material}

Refer to Web version on PubMed Central for supplementary material.

\section{ACKNOWLEDGMENTS}

We are grateful to the patients and their families for their valuable contributions to our study. The work of S.A.S., B.J.B, N.G., and B.P.A was supported by the Intramural Research Program of the Division of Cancer Epidemiology and Genetics, National Cancer Institute, National Institutes of Health, and by contract HHSN261201100018C with Westat, Inc. The authors would like to thank Lisa Leathwood, RN, Maureen Risch, RN, and Ann Carr, MS, CGC, and other members of the Westat Inherited Bone Marrow Failure Syndromes team for their assistance. S.C.C. acknowledges research support from the Intramural Research Program of National Human Genome Research Institute, National Institutes of Health.

\section{REFERENCES}

Alter BP, Giri N, Savage SA, Peters JA, Loud JT, Leathwood L, Carr AG, Greene MH, Rosenberg PS. 2010 Malignancies and survival patterns in the National Cancer Institute inherited bone marrow failure syndromes cohort study. Br J Haematol 150:179-188. [PubMed: 20507306]

Alter BP, Rosenberg PS. 2013 VACTERL-H association and Fanconi anemia. Mol Syndromol 4:8793. [PubMed: 23653579]

Ballew BJ, Yeager M, Jacobs K, Giri N, Boland J, Burdett L, Alter BP, Savage SA. 2013 Germline mutations of regulator of telomere elongation helicase 1, RTEL1, in Dyskeratosis congenita. Hum Genet 132:473-480. [PubMed: 23329068]

Bogliolo M, Schuster B, Stoepker C, Derkunt B, Su Y, Raams A, Trujillo JP, Minguillon J, Ramirez MJ, Pujol R, Casado JA, Banos R, Rio P, Knies K, Zuniga S, Benitez J, Bueren JA, Jaspers NG, Scharer OD, de Winter JP, Schindler D, Surr alles J. 2013 Mutations in ERCC4, encoding the DNArepair Endonuclease XPF, cause Fanconi anemia. Am J Hum Genet 92:800-806. [PubMed: 23623386]

Chandrasekharappa SC, Lach FP, Kimble DC, Kamat A, Teer JK, Donovan FX, Flynn E, Sen SK, Thongthip S, Sanborn E, Smogorzewska A, Auerbach AD, Ostrander EA. 2013 Massively parallel sequencing, aCGH, and RNA-Seq technologies provide a comprehensive molecular diagnosis of Fanconi anemia. Blood 121:e138-e148. [PubMed: 23613520]

Colnaghi L, Jones MJ, Cotto-Rios XM, Schindler D, Hanenberg H, Huang TT. 2011 Patient-derived Cterminal mutation of FANCI causes protein mislocalization and reveals putative EDGE motif function in DNA repair. Blood 117:2247-2256. [PubMed: 20971953] 
Dorsman JC, Levitus M, Rockx D, Rooimans MA, Oostra AB, Haitjema A, Bakker ST, Steltenpool J, Schuler D, Mohan S, Schindler D, Arwert F, Pals G, Mathew CG, Waisfisz Q, de Winter JP, Joenje H. 2007 Identification of the Fanconi anemia complementation group I gene, FANCI. Cell Oncol 29:211-218. [PubMed: 17452773]

Faivre L, Portnoi MF, Pals G, Stoppa-Lyonnet D, Le Merrer M, Thauvin- Robinet C, Huet F, Mathew CG, Joenje H, Verloes A, Baumann C. 2005 Should chromosome breakage studies be performed in patients with VACTERL association? Am J Med Genet A 137A:55-58.

Fargo JH, Rochowski A, Giri N, Savage SA, Olson SB, Alter BP. 2014 Comparison of chromosome breakage in non-mosaic and mosaic patients with Fanconi anemia, relatives, and patients with other inherited bone marrow failure syndromes. Cytogenet Genome Res 144:15-27. [PubMed: 25227706]

Hira A, Yoshida K, Sato K, Okuno Y, Shiraishi Y, Chiba K, Tanaka H, Miyano S, Shimamoto A, Tahara H, Ito E, Kojima S, Kurumizaka H, Ogawa S, Takata M, Yabe H, Yabe M. 2015 Mutations in the gene encoding the E2 conjugating enzyme UBE2T cause Fanconi anemia. Am J Hum Genet 96:1001-1007. [PubMed: 26046368]

Joo W, Xu G, Persky NS, Smogorzewska A, Rudge DG, Buzovetsky O, Elledge SJ, Pavletich NP. 2011 Structure of the FANCI-FANCD2 complex: Insights into the Fanconi anemia DNA repair pathway. Science 333:312-316. [PubMed: 21764741]

Kitao H, Takata M. 2011 Fanconi anemia: A disorder defective in the DNA damage response. Int J Hematol 93:417-424. [PubMed: 21331524]

Kocak H, Ballew BJ, Bisht K, Eggebeen R, Hicks BD, Suman S, O’Neil A, Giri N, Laboratory NDCGR, Group NDCSW, Maillard I, Alter BP, Keegan CE, Nandakumar J, Savage SA. 2014 Hoyeraal-Hreidarsson syndrome caused by a germline mutation in the TEL patch of the telomere protein TPP1. Genes Dev 28:2090-2102. [PubMed: 25233904]

Levitus M, Rooimans MA, Steltenpool J, Cool NF, Oostra AB, Mathew CG, Hoatlin ME, Waisfisz Q, Arwert F, de Winter JP, Joenje H. 2004 Heterogeneity in Fanconi anemia: Evidence for 2 new genetic subtypes. Blood 103:2498-2503. [PubMed: 14630800]

Naipal KA, Verkaik NS, Ameziane N, van Deurzen CH, Ter Brugge P, Meijers M, Sieuwerts AM, Martens JW, O’Connor MJ, Vrieling H, Hoeijmakers JH, Jonkers J, Kanaar R, de Winter JP, Vreeswijk MP, Jager A, van Gent DC. 2014 Functional ex vivo assay to select homologous recombination-deficient breast tumors for PARP inhibitor treatment. Clin Cancer Res 20:48164826. [PubMed: 24963051]

Sawyer SL, Tian L, Kahkonen M, Schwartzentruber J, Kircher M, University of Washington Centre for Mendelian G, Consortium FC, Majewski J, Dyment DA, Innes AM, Boycott KM, Moreau LA, Moilanen JS, Greenberg RA. 2015 Biallelic mutations in BRCA1 cause a new Fanconi anemia subtype. Cancer Discov 5:135-142. [PubMed: 25472942]

Scheckenbach K, Morgan M, Filger-Brillinger J, Sandmann M, Strimling B, Scheurlen W, Schindler D, Gobel U, Hanenberg H. 2012 Treatment of the bone marrow failure in Fanconi anemia patients with danazol. Blood Cells Mol Dis 48:128-131. [PubMed: 22178060]

Shimamura A, Alter BP. 2010 Pathophysiology and management of inherited bone marrow failure syndromes. Blood Rev 24:101-122. [PubMed: 20417588]

Sims AE, Spiteri E, Sims RJ 3rd, Arita AG, Lach FP, Landers T, Wurm M, Freund M, Neveling K, Hanenberg H, Auerbach AD, Huang TT. 2007 FANCI is a second monoubiquitinated member of the Fanconi anemia pathway. Nat Struct Mol Biol 14:564-567. [PubMed: 17460694]

Smogorzewska A, Matsuoka S, Vinciguerra P, McDonald ER 3rd, Hurov KE, Luo J, Ballif BA, Gygi SP, Hofmann K, D'Andrea AD, Elledge SJ. 2007 Identification of the FANCI protein, a monoubiquitinated FANCD2 paralog required for DNA repair. Cell 129:289-301. [PubMed: 17412408]

Solomon BD, Pineda-Alvarez DE, Raam MS, Bous SM, Keaton AA, Velez JI, Cummings DA. 2010 Analysis of component findings in 79 patients diagnosed with VACTERL association. Am J Med Genet A 152A:2236-2244. [PubMed: 20683998]

Vetro A, Iascone M, Limongelli I, Ameziane N, Gana S, Della Mina E, Giussani U, Ciccone R, Forlino A, Pezzoli L, Rooimans MA, van Essen AJ, Messa J, Rizzuti T, Bianchi P, Dorsman J, de Winter JP, Lalatta F, Zuffardi O. 2015 Loss-of-function FANCL mutations associate with severe Fanconi anemia overlapping the VACTERL association. Hum Mutat 36:562-568. [PubMed: 25754594] 


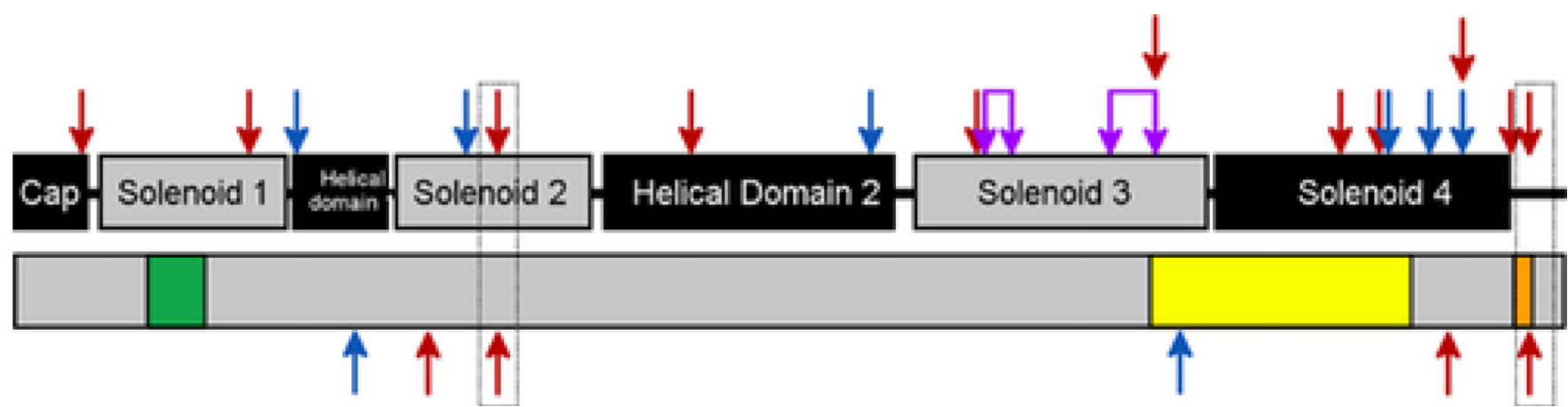

Figure 1:

Schematic of the FANCI gene and location of reported mutations. The downward pointing arrows on the top of the schematic represent the location of mutations reported in the literature. The upward pointing arrows at the bottom of the schematic represent the locations of the mutations in the three new patients reported here. Red arrows indicate premature stop codons (nonsense or frameshift mutations). Blue arrows represent missense mutations.

Purple arrows represent in-frame deletions. The top schematic shows the structural domains of FANCI, while the bottom schematic shows the relative positions of the FANCI functional domains (leucine zipper [green], ARM repeats [yellow], and EDGE motif [orange]). 


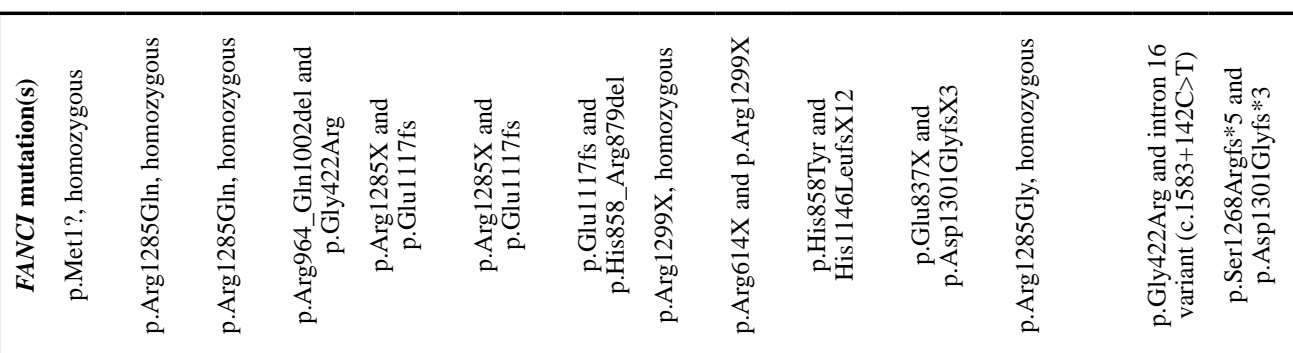

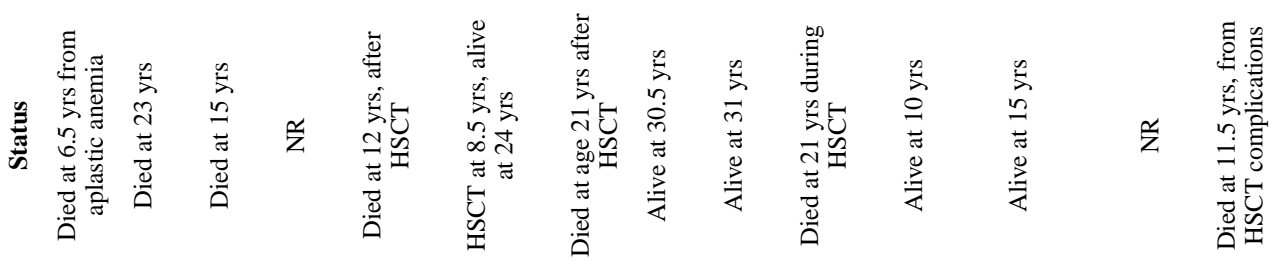

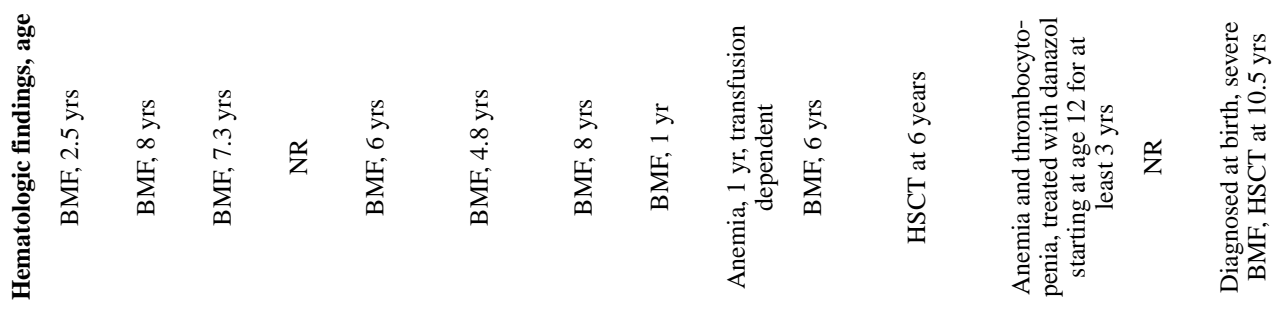

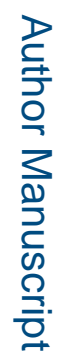

永

空
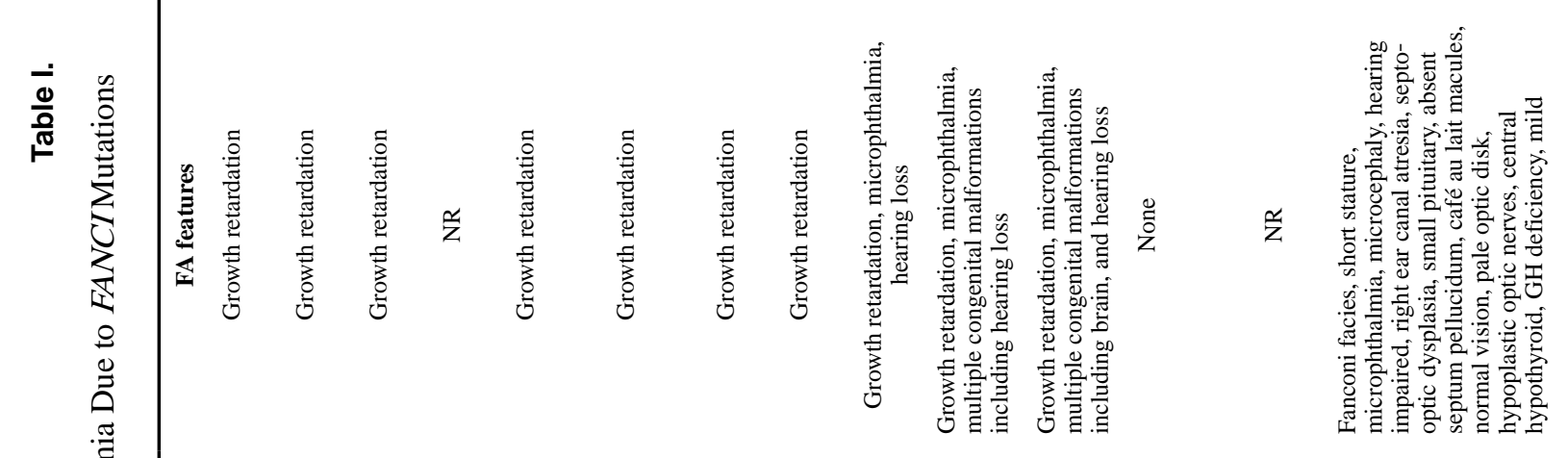

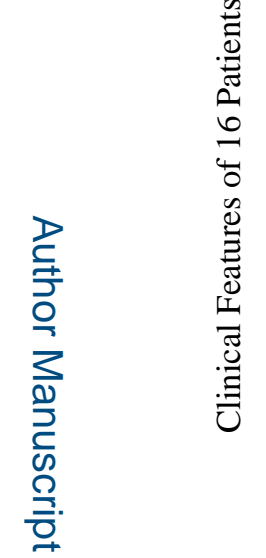
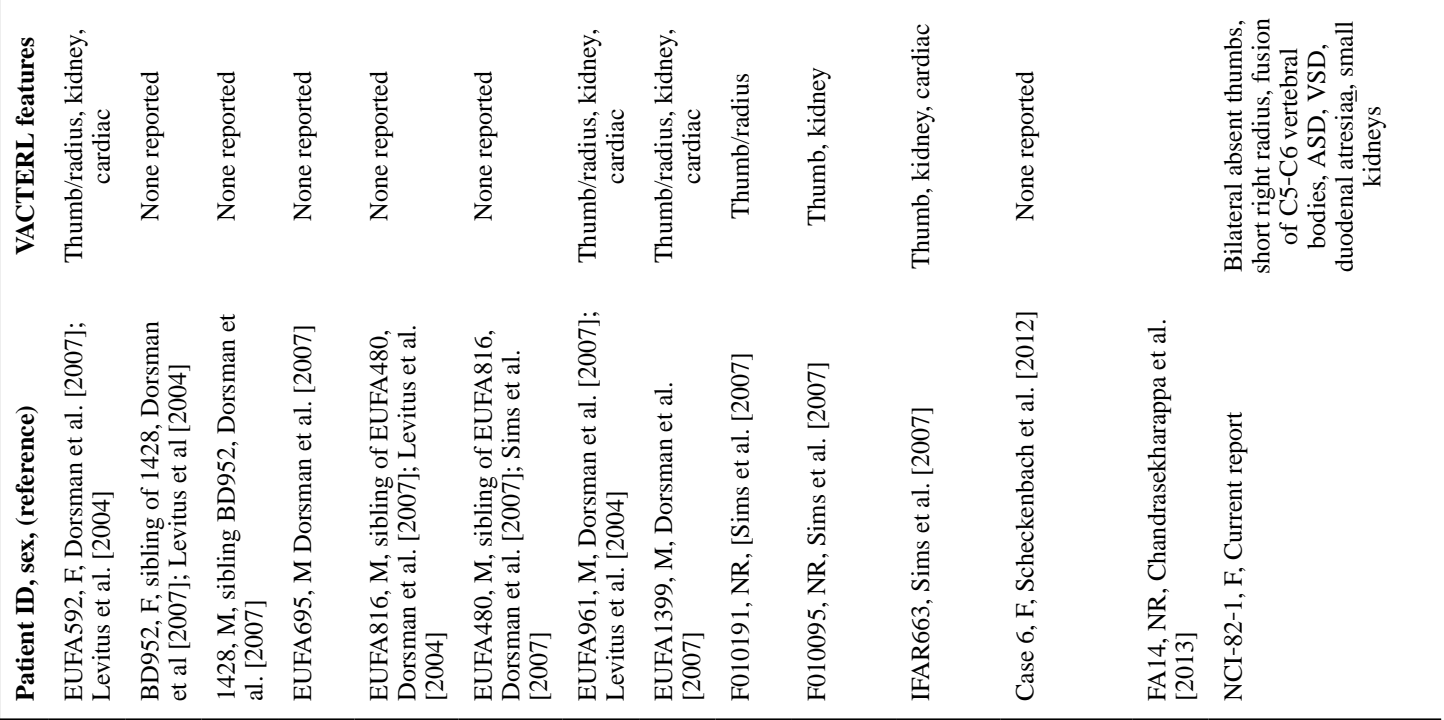

Am J Med Genet A. Author manuscript; available in PMC 2020 April 15. 


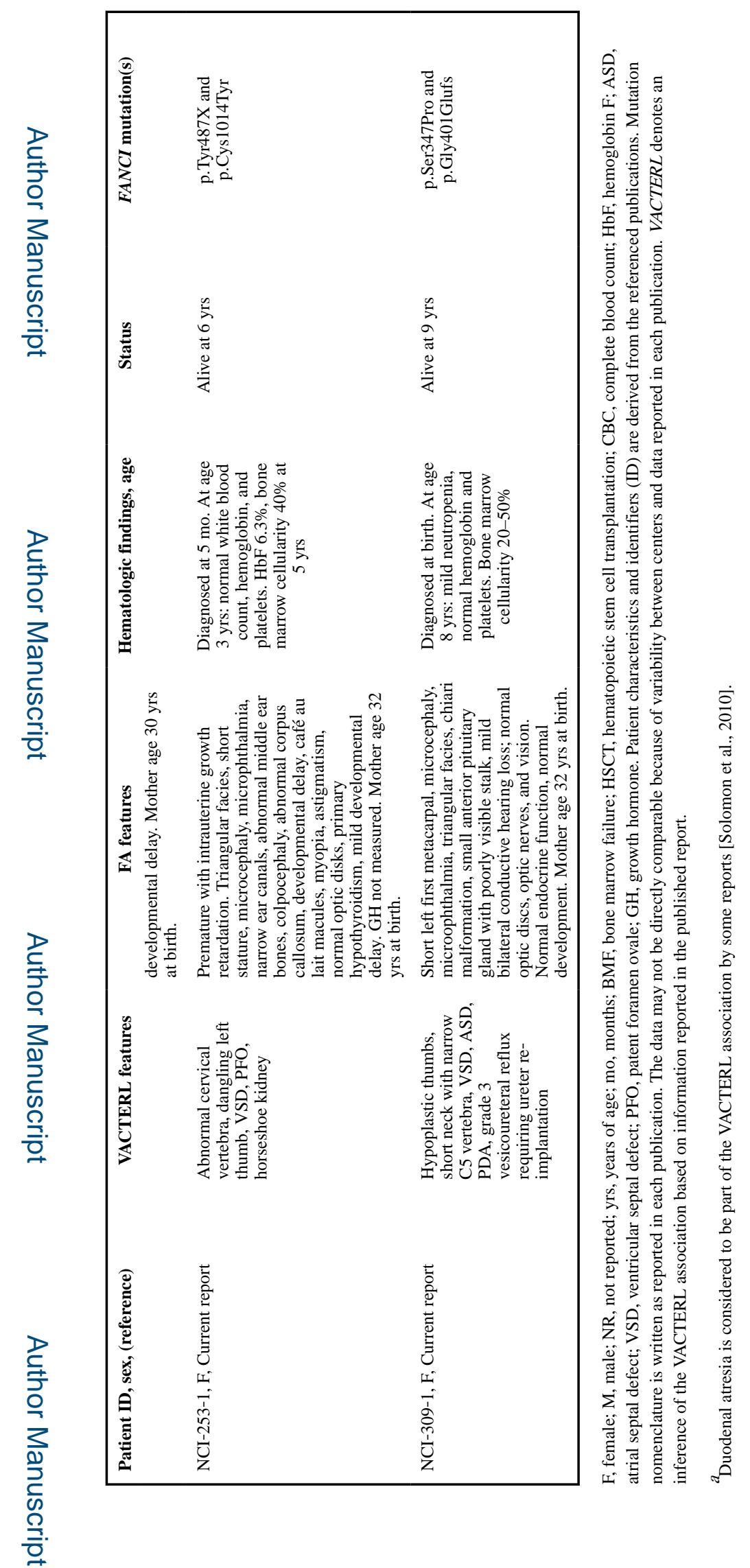

Am J Med Genet A. Author manuscript; available in PMC 2020 April 15. 